\title{
Social Protection to Address the Drivers of Vulnerability: A Bridge too Far?
}

\author{
Keetie Roelen
}

\begin{abstract}
Social protection has moved high up on the development agenda and is increasingly considered to be an inherent part of the response to poverty reduction. At the same time, it has received criticism for its current tools and interventions not appropriately taking account of social differentiation and differential access to services. This overview addresses questions around the potential of social protection to be more ambitious and actually address underlying drivers of vulnerability across demographic and social groups. It does so by discussing the need for social protection to be 'sensitive' and concurrent issues around political commitment, practical implementation and understandings of impact of social protection.
\end{abstract}

Social protection is now widely recognised to be more than a purely monetary or material response to support people living in poverty and hardship. The ' $3 \mathrm{P}$ ' terminology, envisioning social protection as being protective, preventive and promotive, has gained considerable traction with academics and policymakers in recent years - as illustrated by its inclusion in the World Bank's new strategy on social protection and labour (World Bank 2011) - and reflects the broad role that social protection has to play. Nevertheless, the question arises as to whether we can expect even more from social protection. As SabatesWheeler and Roelen (2011) argue, the rise of social protection as a central element in development policy has been accompanied by deserved criticism that popular instruments and programmes of social protection have not paid adequate attention to social differentiation and differential access to opportunities for different social or age-specific groups. Programmes can help the poor and vulnerable to survive, cope and mitigate effects of shocks, and in some cases can even 'graduate' the poor out of poverty.

But can we also expect social protection to go beyond cushioning the effects of poverty and hardship, and also to address those underlying issues that perpetuate and reinforce patterns of poverty and vulnerability? In other words, can we demand that social protection should carry a degree of transformation, through addressing differential needs and vulnerabilities and responding to the structural inequalities that lock people into their situations of hardship? Four articles are brought together in this IDS Bulletin to advance the discussion of social protection's potential to be more aspirational and 'transformative' in addressing differential vulnerabilities and their underlying drivers.

An expanding body of research discusses the need for social protection to respond to particular needs and vulnerabilities of different groups in society. 'Sensitive' has become a commonly used adjective in the social protection literature, with notions of gender-, child- and HIV-sensitive social protection, among others. This need to be sensitive follows from the bid to make social protection respond to a wide range of different needs and vulnerabilities, which can diverge across demographic and social groups, to address them appropriately and to provide equal access. Needs can be of a practical or strategic nature, where practical needs arise from the concrete conditions experienced by particular groups and strategic needs originate from limited autonomy and relative invisibility within the population at large (as applied to the case of children in Sabates-Wheeler and Roelen 2011). 
In this IDS Bulletin, Schneider et al. discuss differential and strategic needs, and thereby particular requirements from social protection, resulting from disability. The acknowledgement that disability is an issue to be tackled within the development debate is now slowly gaining momentum with the recent publication of the first World Report on Disability (WHO and World Bank 2011), the first document to provide a picture about disability worldwide. Jones and Holmes discuss the importance of a gendersensitive outlook to social protection. Awareness of gender issues around social protection is more longstanding, with work by Molyneux (2009) and Jones and Holmes (2010) bringing a gender critique. As Moser (1989: 1803) describes, practical gender needs are 'those needs which are formulated from the concrete conditions women experience', while strategic gender needs are 'those needs that are formulated from the analysis of their subordination to men'.

Although strong arguments may call for more tailored responses within social protection to address differential vulnerabilities and their drivers appropriately, practical implementation of 'sensitive' social protection is far from evident. Political commitment and practical implementation are two important issues in translating the identification of needs into an appropriate response. The contribution by Jones and Holmes points us to the difficulties in gaining political traction to make social protection adopt a gender lens and, as such, to be more responsive to underlying patterns of vulnerability for specific groups in society. Difficulties appear to be reflected and compounded by the lack of high-quality and realtime gender-disaggregated data, conflicting interests of key actors and weak institutions leading the agenda on gender issues. These difficulties are not specific to gender only but are also mirrored in other 'sensitive' approaches to social protection, such as child-sensitive social protection. Although children have become increasingly visible on the development agenda and in debates around poverty reduction, they remain a highly invisible population, lacking voice and hard to reach. This lack of institutional visibility is further underlined by the fact that children's issues are by and large represented by the weakest ministries in government. As Jones and Sumner (2011: 67) point out: 'Many developing countries lack a dedicated children's ministry' and in cases where they do exist 'they are typically amongst the least influential and under-resourced'.

Practical issues around assessment of needs and targeting of programme support are another challenge in trying to address such differential needs. Schneider et al. provide an insight into practical concerns around identifying and reaching disabled people with social transfers in Zambia, Uganda and South Africa. Appropriate and transparent assessment tools of disability prove to be key in improving the inclusion of disabled beneficiaries and reducing stigma. Similar issues can be observed when considering $\mathrm{HIV}$-sensitive social protection and targeting benefits to those directly affected by HIV. While a direct transfer to orphans, for example, may prove very useful in providing instant relief and meeting short-term and material needs, it can also have strong implications in terms of stigmatisation and 'commodification' of orphans (Roelen et al. 2011).

Once political and practical constraints are overcome, the question of impact comes into play. Evidence is thin but the contributions in this IDS Bulletin do point towards the extent to which social protection can meet more aspirational and transformative demands, largely with respect to social cash transfers. In terms of disability, Schneider et al. point towards the support that transfers can provide in terms of direct relief. It is also emphasised, however, that social transfers as an exclusive intervention are limited in addressing the particular needs arising from disability, with a strong need to complement transfers with social services. Similarly, Hochfeld and Plagerson find that while the Child Support Grant in South Africa has the potential to increase resilience and promote empowerment of female recipients, these transfers do little to change the structural causes of poverty, such as lack of employment.

Hochfeld and Plagerson's qualitative assessment of the Child Support Grant (CSG) focuses on the aspect of social stigma. The CSG originated from a strong rights-based discourse and political commitment. But social and political support has been eroding over recent years, with negative social discourses taking hold about the grant creating dependency and encouraging childbearing. Interestingly, while female recipients 
indicated that their impoverished situation was primarily vested in structural causes with little blame for themselves, they did hold negative attitudes towards other CSG recipients on issues of laziness, dependency and teenage fertility.

In their contribution, MacAuslan and Riemenschneider also point towards the complex interplay between transfers, stigma and social relations. Given the complex and continuous impact of transfers on poverty and social relations and vice versa, there is a need to reconsider common frameworks of evaluating the impact of cash transfer schemes. While current analyses of cash transfers go a long way in addressing issues of stigma and resentment around the receipt of such transfers, they call for more profound analyses of consequent changes in behaviour at individual, community and macro-level. This call is reinforced by findings from Zimbabwe and Malawi that suggest that cash transfer schemes can have far-reaching impacts on social relations, both positive and negative.

Together, the collection of contributions on this theme point towards the potential of social protection in responding to differential needs and addressing drivers of vulnerability, but also towards the difficulties and limitations along the

\section{References}

Jones, N. and Holmes, R. (2010) 'The Politics of Gender and Social Protection', ODI Briefing Paper 62, London: Overseas Development Institute

Jones, N. and Sumner, A. (2011) Child Poverty: Evidence and Policy, Bristol: Policy Press

Molyneux, M. (2009) 'Two Cheers for CGTS', IDS Bulletin 38.3: 69-74

Moser, C. (1989) 'Gender Planning in the Third World: Meeting Practical and Strategic Gender Needs', World Development 7.2: 1799-825

Roelen, K.; Edstrom, J.; Sabates-Wheeler, R. and Davies, M. (2011) Child and HIV Sensitive Social Protection in Eastern and Southern Africa: Lessons from the Children and AIDS Regional Initiative way. Although social protection cannot alter the very situation that puts people at higher risk, such as being disabled or being a girl, it does have an important role to play in reducing the level of vulnerability to which people are exposed. That said, it is also important to acknowledge that social protection cannot stand on its own and needs to be strongly vested in wider macroeconomic and labour market policies. Important drivers of vulnerability are structural rather than individual and thus require a broad and comprehensive response. Furthermore, its effects reach far beyond direct and material impacts but also influence behaviour and social relations.

Finally, changing perceptions and the concurrent rise in negative discourses about welfare recipients will also reflect on commitment and support to social protection, and transfers in particular, at the political and social levels. To avoid losing the momentum around the role of cash transfers in poverty reduction, and the opportunity to build upon that for a more aspirational and transformative role for social protection, we need to expand and strengthen the evidence and invest in formulating more solid and positive narratives.

(CARI), Nairobi: United Nations Children's Fund, Eastern and Southern African Region (UNICEF ESARO)

Sabates-Wheeler, R. and Roelen, K. (2011)

'Transformative Social Protection

Programming for Children and their Carers: A Gender Perspective', Gender and Development 19.2: 179-94

WHO and World Bank (2011) World Report on Disability, New York: World Health Organization (WHO)

World Bank (2011) Building Resilience and Opportunity: The World Bank's Social Protection and Labor Strategy 2012-2022: Concept Note, Washington DC: World Bank 